\title{
Author Correction: A 300,000-year-old throwing stick from Schöningen, northern Germany, documents the evolution of human hunting
}

Nicholas J. Conard (D, Jordi Serangeli, Gerlinde Bigga and Veerle Rots

Correction to: Nature Ecology \& Evolution https://doi.org/10.1038/s41559-020-1139-0, published online 20 April 2020.

In the version of this Brief Communication originally published, in the fourth paragraph of the main text, one sentence incorrectly referred to the massive thrusting spear as being made from pine.

The following sentence: 'These wooden tools include multiple throwing spears and a longer, more massive thrusting spear made of pine (Pinus sp.).' should have read as follows: 'These wooden tools include multiple throwing spears and a longer, more massive thrusting spear.'

This error has now been corrected.

Published online: 11 May 2020

https://doi.org/10.1038/s41559-020-1219-1

(C) The Author(s), under exclusive licence to Springer Nature Limited 2020 